\title{
Stable Cr isotope systematics of carbonatites from the East African Rift
}

\author{
ROBERT FREI ${ }^{1}$, TOMÁŠ MAGNA ${ }^{2}$, VLADISLAV RAPPRICH ${ }^{2}$ \\ ${ }^{1}$ University of Copenhagen, Copenhagen, Denmark; \\ robertf@ign.ku.dk \\ ${ }^{2}$ Czech Geological Survey, Prague, Czech Republic
}

Chromium is among key elements for deciphering processes such as magmatic differentiation, crustal contamination, low-temperature alteration etc. Carbonatites are generally considered to represent lower-temperature derivative melts from the mantle but the source of carbon may, in part, be located in a subducting assemblage. Irrespective of their likely mantle origin, the ultimate source of carbonatites can potentially be tested using stable $\mathrm{Cr}$ isotope systematics because ocean floor carbonates may acquire isotopically fractionated $\mathrm{Cr}$ compared with the original unmodified lithology. If subducted into the mantle, these rocks could plausibly introduce measurable $\mathrm{Cr}$ isotope effects in geologically opportune situations although lowtemperature carbonates commonly are depleted in $\mathrm{Cr}$ and much of $\mathrm{Cr}$ would be buffered by silicates.

Here, we report on the preliminary results of the determination of $\mathrm{Cr}$ contents and stable $\delta^{53} \mathrm{Cr}$ compositions using a double-spike approach, combined with TIMS analysis, in a suite of carbonatites from Uganda, associated with the East African Rift (EAR). Carbonate fractions (released using $\mathrm{HCl}$ leaching) often have higher $\mathrm{Cr}$ contents than the non-carbonate residual phase (occasionally up to $\sim 10 \times$ ). In rare cases, non-carbonate fractions were enriched in Cr. For all samples from EAR, carbonate fractions show slightly higher $\delta^{53} \mathrm{Cr}$ values than the coexisting silicate fractions; however, in all cases, their $\delta^{53} \mathrm{Cr}$ values are entirely in the range of the upper mantle. High-temperature stable $\mathrm{Cr}$ isotope fractionation between carbonate and non-carbonate portion $\Delta^{53} \mathrm{Cr}_{\mathrm{C}-\mathrm{NC}}=0.04-0.08 \%$. This indicates derivation of carbonatitic magmas at EAR from the mantle, with a limited influence of other reservoirs. In contrast, selected samples from south India and Oka (Canada) show much higher $\Delta^{53} \mathrm{CrC}_{\mathrm{NC}}>0.12$ and up to 0.29 , clearly attesting to either a different source of carbonate or disequilibrium between carbonate and non-carbonate portions. In particular, a carbonatite sample from Mountain Pass shows strongly shifted $\delta^{53} \mathrm{Cr}$ values in both carbonate and non-carbonate fraction, far above the commonly accepted mantle range, and reversed $\Delta{ }^{53} \mathrm{Cr}_{\mathrm{C}-\mathrm{NC}}=-0.16 \%$.

Supported by the Czech Science Foundation (19-29124X). 